by Novellino and colleagues, ${ }^{3}$ several video-assisted thoracoscopic extended thymectomy procedures with varying numbers of port incisions have been proposed, according to the experience and the preference of surgeons. The uniportal thoracoscopic approach was described initially by Rocco and associates ${ }^{4}$ in 2004 for minor thoracic and pulmonary procedures. Since then, it has been used for other more complex procedures, including lobectomy, pneumonectomy, and bronchoplastic resection. During video-assisted thoracoscopic extended thymectomy, multiple port incisions force the surgeon to an unnatural eye-hand coordination relative to what must be done in open surgery. In addition, articulating graspers and endostaplers contribute to avoid interference of the thoracoscope and instrumentation. ${ }^{5}$ Conversely, a uniportal approach allows the maximal exposure of the anterior mediastinum that is crucial for resection of thymus and facilitates the view of cardiophrenic space, an area not always easily accessible, for performing a complete resection of mediastinal fat. In addition, through the same access the superior horns of the thymus can easily be pulled down, with complete exposure of innominate veins. All surgical dissection and the complete clearance of the mediastinal fat were achieved with the harmonic scalpel, which was also used for the division of small vessels (the larger vessels were endoscopically ligated and divided).

In conclusion, uniportal bilateral thoracoscopic extended thymectomy is a feasible procedure and may be a valid development of video-assisted thoracoscopic extended thymectomy. Obviously, our impression should be validated by further larger studies in terms of reproducibility and clinical results.

\section{References}

1. Shiono H, Kadota Y, Hayashi A, Okumura M. Comparison of outcomes after extended thymectomy for myasthenia gravis: bilateral thoracoscopic approach versus sternotomy. Surg Laparosc Endosc Percutan Tech. 2009;19: 424-7.

2. Caronia F, Fiorelli A, Monte AL. Bilateral thoracoscopic thymectomy using a novel positioning system. Asian Cardiovasc Thorac Ann. 2014;22:1135-7.

3. Novellino L, Longoni M, Spinelli L, Andretta M, Cozzi M, Faillace G, et al. "Extended" thymectomy without sternotomy, performed by cervicotomy and thoracoscopic technique in the treatment of myasthenia gravis. Int Surg. 1994; 79:378-81.

4. Rocco G, Martin-Ucar A, Passera E. Uniportal VATS wedge pulmonary resections. Ann Thorac Surg. 2004;77:726-8.

5. Rocco G. VATS and Uniportal VATS: a glimpse into the future. $J$ Thorac Dis 2013;5(Suppl 3):S174.

\title{
Pleurectomy and decortication for metastatic renal cell carcinoma
}

\author{
Aaron Bettenhausen, BS, ${ }^{\mathrm{a}}$ Masatsugu Hamaji, MD, ${ }^{\mathrm{b}}$ Bryan M. Burt, MD, ${ }^{\mathrm{c}}$ and Syed Osman Ali, MD, ${ }^{\mathrm{a}, \mathrm{d}}$ \\ Grand Forks, ND, Kyoto, Japan, and Houston, Tex
}

Pleurectomy and decortication is traditionally indicated for the resection of primary pleural tumors, such as malignant pleural mesothelioma. It is less commonly used for resection of metastatic disease. We present a case of pleurectomy and decortication for metastatic renal cell carcinoma (RCC) confined to the pleural space.

\footnotetext{
From the a Department of Surgery, University of North Dakota School of Medicine and Health Sciences, Grand Forks, ND; the ${ }^{\mathrm{b}}$ Department of Thoracic Surgery, Kyoto University Hospital, Kyoto, Japan; the ${ }^{\mathrm{c}}$ Department of General Thoracic Surgery, Baylor College of Medicine, Houston, Tex; and the ${ }^{\mathrm{d}}$ Department of Cardiovascular and Thoracic Surgery, Altru Hospital, Grand Forks, ND.

Disclosures: Authors have nothing to disclose with regard to commercial support.

Received for publication April 7, 2015; revisions received April 19, 2015; accepted for publication May 2, 2015.

Address for reprints: Aaron Bettenhausen, BS, 2961 24th Ave S No. 204, Grand

Forks, ND 58201 (E-mail: aaron.b.bettenhausen@my.und.edu).

J Thorac Cardiovasc Surg 2015;150:e3-5

$0022-5223 / \$ 36.00$

Copyright (C) 2015 by The American Association for Thoracic Surgery

http://dx.doi.org/10.1016/j.jtcvs.2015.05.007
}

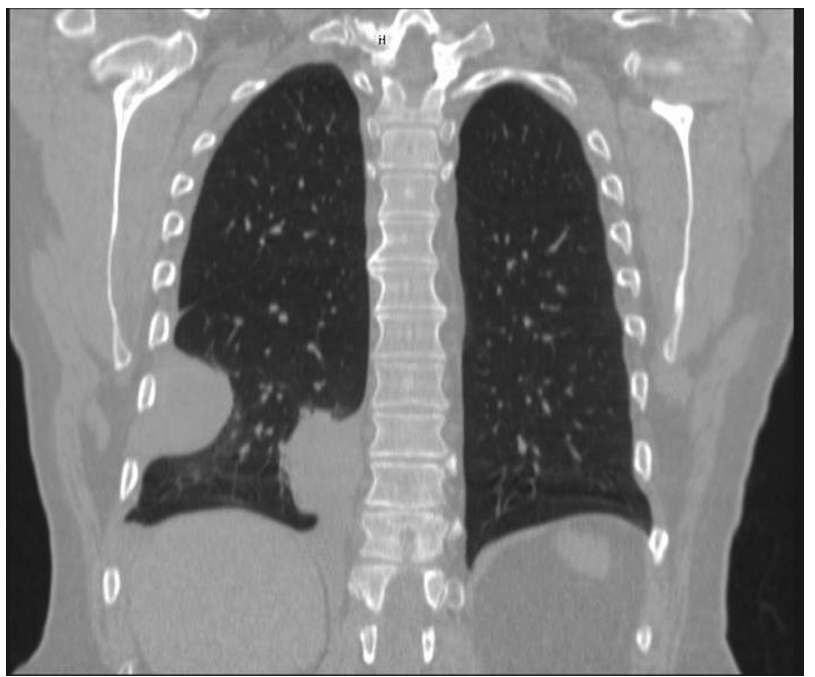

FIGURE 1. Chest computed tomography illustrating multiple pleuralbased masses. 


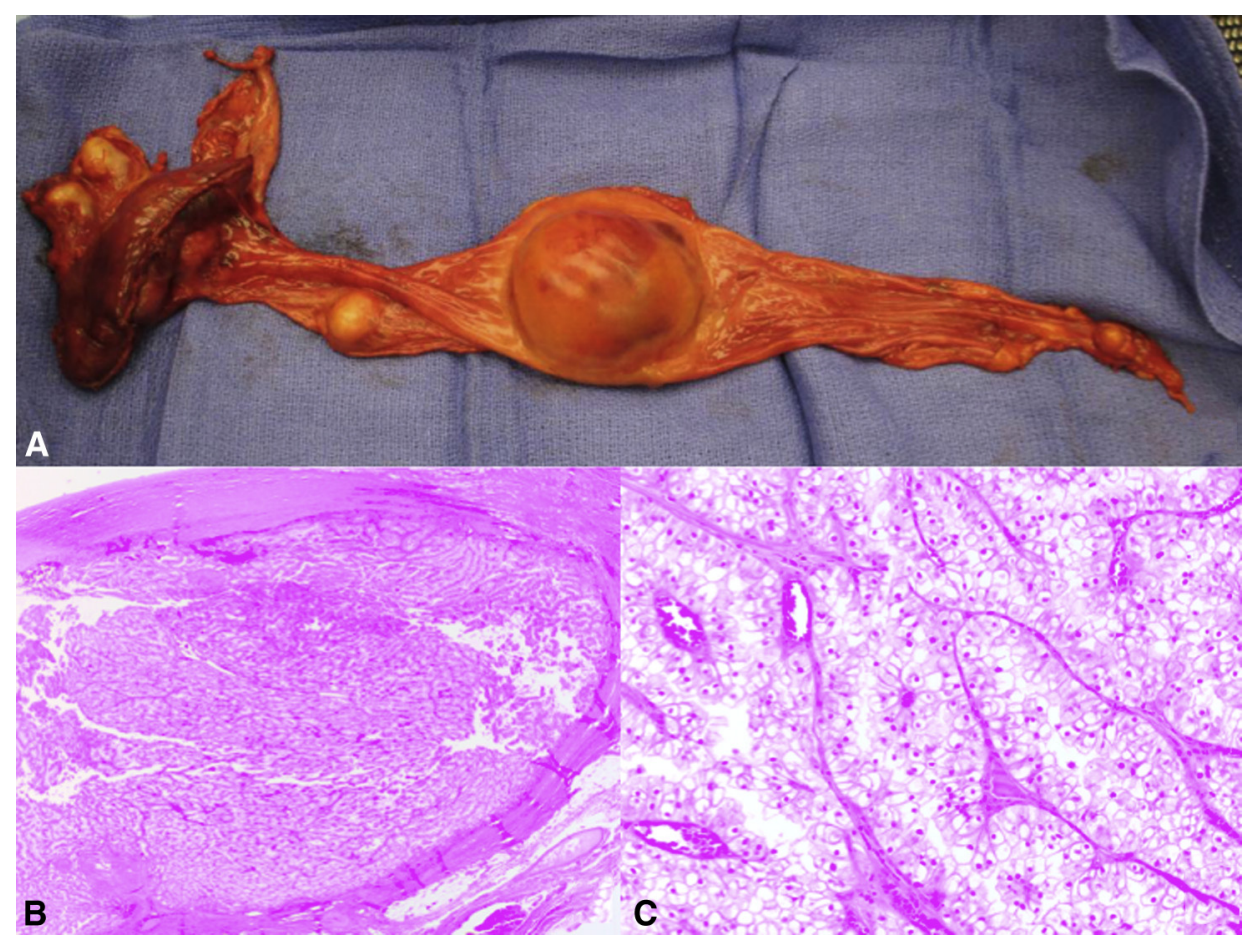

FIGURE 2. A, Parietal pleura with 6 nodules. B, Low-power micrograph. C, High-power micrograph.

\section{CLINICAL SUMMARY}

A 75-year-old man with a history of RCC was referred with shortness of breath in the setting of multiple rightsided, pleural-based masses. Chest computed tomography (CT) imaging demonstrated multiple pleural deposits ranging in size from 1.3 to $6.6 \mathrm{~cm}$, without evidence of parenchymal lung disease (Figure 1). Ten years previously he had undergone an open radical nephrectomy with negative margins for a stage II renal cell carcinoma (RCC), clear cell type. A CT-guided biopsy of the largest pleural mass confirmed the diagnosis of metastatic RCC. Further diagnostic imaging, including positron emission tomography, CT, and bone scan revealed no evidence of extrathoracic disease. The patient subsequently underwent 1 month of daily oral pazopanib (discontinued because of elevated results of liver function tests), then 2 months of daily oral axitinib (discontinued for severe hypertension), followed by 9 cycles of temsirolimus (discontinued for hepatotoxicity). Throughout these treatments, the largest lesion remained stable at $6.6 \times 3.5 \mathrm{~cm}$. Preoperative pulmonary function testing revealed a forced expiratory volume in 1 second of $2.43 \mathrm{~L}$ ( $76 \%$ of predicted) and a diffusing capacity of the lung for carbon dioxide of $19.68 \mathrm{~mL} / \mathrm{min} / \mathrm{mm} \mathrm{Hg}$ ( $73 \%$ of predicted). Because of confinement of his disease to the pleural space and his excellent performance status, a pleurectomy and decortication procedure was advised and accepted as a means of metastasectomy.
The patient was taken to the operating room, and a pleurectomy and decortication procedure was performed as described for malignant pleural mesothelioma by Sugarbaker and colleagues. ${ }^{1}$ A right extended posterolateral thoracotomy was performed, with resection of the sixth rib to aid exposure. Extrapleural dissection was carried inferiorly, where a large pleural mass was palpated and dissected off of the chest wall. The dissection was then continued to the right hemidiaphragm, where 2 smaller masses were palpated on the pleural surface of the diaphragm itself. A 5-cm diaphragmatic segment was resected en bloc to ensure negative margins and repaired with 2-mm thick polytetrafluoroethylene mesh (Gore-Tex Dual Mesh; W. L. Gore \& Associates, Inc, Flagstaff, Ariz). The dissection then proceeded medially, and 2 additional masses adjacent to the posterior mediastinum near the esophagus were identified and resected. The largest of the pleural tumors was found to invade the parenchyma of the right lower lobe basilar segments; a limited pulmonary wedge resection was therefore incorporated into the resection (Figure 2, A). Intraoperative frozen-section analysis of the specimen showed complete pleural encasement of these tumors.

The operation was concluded, and the patient was discharged home on postoperative day 7. Formal pathologic examination of the resected tissue found 6 pleural nodules (Figure 2, A), all RCC of the clear type 
(Figure 2, $B$ and $C$ ). The patient's dyspnea has since resolved. For the past 18 months, the patient has had no evidence of disease with regular follow-ups with surveillance CT scans.

\section{DISCUSSION}

Recurrent metastatic disease after nephrectomy for RCC is relatively common, occurring in $20 \%$ to $50 \%$ of patients. The prognosis of metastatic RCC is poor, demonstrating a 6- to 12 -month median overall survival and a $10 \%$ to $20 \%$ 2-year overall survival. ${ }^{2}$ The lungs are the most common location for RCC metastases, accounting for the location of $45 \%$ to $75 \%$ of all metastatic disease. ${ }^{3}$ Pulmonary metastasectomy appears to yield favorable results in certain patients, although these individuals largely have a high performance status with generous pulmonary reserve. Moreover, the biology of the cancer is important, because patients with shorter disease-free intervals and those with large $(>3 \mathrm{~cm})$ metastases have poorer outcomes.

Pleural metastases of RCC are relatively rare. ${ }^{4,5}$ Autopsy data have demonstrated that $12 \%$ of all patients with metastatic RCC have pleural involvement, involvement that is invariably associated with pulmonary metastasis. ${ }^{4}$
While cases of pleural RCC metastasis are generally thought to occur from direct extension of lung parenchymal RCC metastases, some cases of pleural RCC, such as that described here, occur without lung metastases. In such cases, it has been suggested that pleural metastases may occur by way of the Batson venous plexus. ${ }^{5}$ Although pulmonary metastasectomy is considered by many to be reasonable for metastatic parenchymal RCC, a pleurectomy and decortication procedure for pleural RCC metastases has never been reported to the best of our knowledge. We present here a case study of a pleurectomy and decortication procedure for pleural metastatic RCC that provided excellent symptom relief and local control.

\section{References}

1. Sugarbaker DJ, Wolf AS. Surgery for malignant pleural mesothelioma. Expert Rev Respir Med. 2010;4:363-72.

2. Flanigan RC, Campbell SC, Clark JI, Picken MM. Metastatic renal cell carcinoma. Curr Treat Options Oncol. 2003;4:385-90.

3. Kim DY, Karam JA, Wood CG. Role of metastasectomy for metastatic renal cell carcinoma in the era of targeted therapy. World J Urol. 2014;32:631-42.

4. Saitoh H. Distant metastasis of renal adenocarcinoma. Cancer. 1981;48: 1487-91.

5. Ohnishi H, Abe M, Hamada H, Yokoyama A, Hirayama T, Ito R, et al. Metastatic renal cell carcinoma presenting as multiple pleural tumours. Respirology. 2005;10: 128-31.

\title{
The hepatic buttress: A novel surgical technique to treat an intrapericardial diaphragmatic defect after hybrid myocardial ablation
}

\author{
William C. Chapman, Jr, BA, ${ }^{a}$ Michael Sosin, MD, ${ }^{\mathrm{b}}$ J. R. Salameh, MD, FACS, ${ }^{\mathrm{a}, \mathrm{c}}$ and
}

C. Francisco Espinel, MD, FACS, ${ }^{a, c}$ Washington, DC, and Arlington, Va

Multiple medical and interventional therapies are currently available for correcting persistent atrial fibrillation. One such procedure, hybrid ablation, aims to decrease postablative atrial fibrillation relapse by combining transvenous

\footnotetext{
From the ${ }^{\mathrm{a}}$ Georgetown University School of Medicine, Washington, DC; the

${ }^{\mathrm{b}}$ Department of Surgery, Medstar Georgetown University Hospital, Washington, DC; and ${ }^{\mathrm{c}}$ Surgical Specialists, Virginia Hospital Center, Arlington, Va.

Disclosures: Authors have nothing to disclose with regard to commercial support.

Received for publication Feb 1, 2015; revisions received Feb 25, 2015; accepted for publication March 30, 2015; available ahead of print May 7, 2015.

Address for reprints: C. Francisco Espinel, MD, FACS, Virginia Hospital Center, 1625 N George Mason Dr, Suite 334, Arlington, VA 22205 (E-mail: cfespinel@ virginiahospitalcenter.com).

J Thorac Cardiovasc Surg 2015;150:e5-7

$0022-5223 / \$ 36.00$

Copyright (C) 2015 by The American Association for Thoracic Surgery

http://dx.doi.org/10.1016/j.jtcvs.2015.03.065
}

endocardial ablation with surgical scarring of the epicardium. ${ }^{1}$ Recent reports suggest superior outcomes relative to stand-alone transvenous or surgical ablation and an overall complication rate of $4.1 \%$ to $11 \% .^{1,2}$ Reported complications include bleeding, myocardial edema, cardiac tamponade, atrioesophageal fistula, esophageal perforation from thermal injury, and sternotomy. ${ }^{1}$

The following account details a case of herniated small bowel within an intrapericardial diaphragmatic defect after hybrid myocardial ablation through a subxiphoid approach, ultimately resulting in small-bowel obstruction. Treatment involved laparoscopic reduction of herniated bowel, primary repair of the defect, and buttressing the closure with the left triangular ligament of the liver. The purpose of this case is to highlight a previously unreported 